\title{
Einstein: disagreement delays publication of collected works
}

\section{David Dickson reports on the circumstances that have delayed the publication of Albert Einstein's collected writings, which fill 28 file drawers at Princeton University}

Plans to produce a multi-volume edition of Albert Einstein's published and unpublished writings are virtually at a standstill following the failure of the trustees of Einstein's estate, the Princeton University Press, and the project's editor to agree on mutually acceptable terms under which the editorial work can proceed.

Already a project funded by the National Science Foundation, whose initial purpose was to prepare the papers for publication, has had to be revised to the more modest goal of indexing and preparing duplicate copies of the papers. These are kept at the Institute for Advanced Studies in Princeton, where Einstein worked after coming to the USA.

There are no plans at present for the NSF to provide further support for the project after the current contract of the editor of the collected works, Professor John Stachel, expires on 14 July. Nor has the university press announced how it plans to pursue the project after this date.

The trustees of Einstein's estate, who have never refused access to the papers by "reputable scholars", have taken great care to ensure that the editorial work is carried out in a way that they feel would have met his approval. (Dr Otto Nathan, one of the two trustees, has expressed strong disapproval of the National Academy of Science's plan to erect a statue of Einstein in Washington, since he claims this is explicitly against the physicist's wishes).

However a number of physicists and historians of science, many of whom are reluctant to be quoted for fear of exacerbating the current situation, are concerned that the trustees have interpreted their responsibilities so rigidly as to restrict a full appreciation of Einstein's contribution to twentieth century science and thought.

Dr Paul Foreman, for example, organiser of a current exhibition on Einstein at the Smithsonian Museum in Washington, has expressed his regret that the trustees have refused, as a matter he claims of "unbending policy", to loan the exhibition letters and photographs from the estate.

Albert Einstein was a prolific writer on both scientific and non-scientific issues. During his lifetime he published 274 scientific papers and 332 papers of a general content; these, and a large quantity of unpublished material, form the archives which currently fill 28 file drawers at Princeton University.

His correspondents range from $\overrightarrow{0}$ scientists such as Erwin Schroedinger, Max Planck, Wolfgang Pauli and Marie Curie, to contemporaries in other fields, such as Sigmund Freud, Bertrand Russell, Franklin Roosevelt and George Bernard Shaw. And some of the letters, particularly to physicists, suggest further avenues of research which Einstein himself was unable to follow.

On his death in 1955, the literary rights to his papers passed to a trust, of which the two trustees are Helen Dukas, his secretary from 1928 to 1955, and Dr Otto Nathan, an economist and close friend who, like Einstein, came to the US as a refugee from Europe. (Under the terms of the will, the beneficiaries of the trust are Miss Dugas and Margot Einstein, his stepdaughter; eventually the estate will pass to the Hebrew University in Jerusalem).

Negotiations over the publication of the collected works began within weeks of Einstein's death. In 1971, the trustees reached an agreement with the Princeton University Press, which had expressed great interest in the project from the very start. And in 1976 the trustees and the press appointed Professor John Stachel, a physicist on leave from Boston University who has recently co-edited selected papers of Leon Rosenfeld, to be the editor.

In the same year, the university press submitted a grant proposal to the National Science Foundation, requesting $\$ 787,300$ over a five-year period to support editorial preparation for the multivolume project. This, they suggested, would be a "fitting monument" to Einstein, and would include all his published and unpublished writings in the original languages, with English translations of some of the more important works.

The foundation agreed to provide initial support to allow Professor Stachel to plan the editorial work, and to establish the general principles of editing the whole project. The foundation awarded $\$ 80,000$ towards this in 1977 and 1978. But difficulties soon arose in agreeing on a work plan that would be acceptable both to the

\section{Sorry, for copyright reasons some images on this page may not be available online}

\section{Prolific writer: 606 papers published}

trustees and to Princeton University press.

Dr Nathan insisted, for example, that only the editor be allowed to handle the original documents, thus making it necessary for Dr Stachel to do much of the work that would otherwise have been done by research assistants. And other areas of disagreement arose over how the editorial work on the documents should proceed.

It soon became clear to the participants that it would be impossible to proceed with the preliminary editorial work plan that had been developed under the NSF grant, or to complete negotiations with the foundation on the initial five-year grant proposal (even though the plan had been endorsed by an editorial advisory board which met to discuss the situation early in 1978).

At the prompting of NSF's review panel, the university press and Professor Stachel approached the foundation again to support the completion of work on a duplicate archive and an index, to make sure that "when the time comes, the editing of the Einstein papers can proceed without the past year-and-a-half being wasted"

The trustees and the press wrote in a joint statement that a duplicate archive was "absolutely necessary for the continuation of the editorial work if we are able to proceed after 14 July 1979 ," but added that "if the work of editing The Writings of Albert Einstein should cease, one copy of the entire duplicate archive will be kept intact and unmarked so that a new editor, when appointed, could use it with confidence".

Work is now almost completed on the material for the duplicate archive being carried out under an NSF grant which runs out on 30 June; so, too, is the preparation of an index to all the 
papers in the archives, the total number of which may be as high as 60,000. And Professor Stachel has also been able to contact many of those who were in correspondence with Einstein, asking for their comments on copies of letters which have been sent to them.

But there the matter rests. $\mathrm{Mr}$ Herbert Bailey, head of the university press, admits that the project has had "problems", and does not accept that it has gone into abeyance. "We have a lot of reasons to think that the project, on which we are as keen as we have always been, will go forward" he said last week; however he declined to reveal how the project will proceed after the NSF grant money, and Professor Stachel's contract, run out in the summer.
Dr Nathan is equally adamant that claims that the trustees have placed unworkable restrictions on how the editing work should proceed are "nonsense", and that the trustees "are being maligned" if such charges are being made.

He says that since a few days after Einstein's death the estate has been attempting to get a complete edition of the physicist's writings published, but that he has been "blocked again and again", and that he feels that "at the moment we do not know where we are going".

Historians of science are hoping that the stalemate can be resolved by some means (there are rumours of possible litigation, but these cannot be confimed). No one disputes that the collected works, when they are eventually published, will be a major contribution to twentieth century scholarship, helping to provide a far greater understanding of Einstein's role in the development of both modern science and the modern world; but few do not express frustration at the current impasse.

"When completed it will be-or should be-what historians and philosophers of science, and others, have been waiting for since Einstein died", Dr Jeremy Bernstein, professor of physics at Stevens Institute of Technology, and author of a biography of Einstein, wrote recently. "Not all this material is of great interest but what matters is that it should be available."

\section{FDA scientists dispute ethics of testing laetrile}

A SCIENTIST with the Food and Drug Administration has filed a "citizen's petition" against his agency in an attempt to prevent it from giving approval to clinical trials which the National Cancer Institute is planning to carry out on the controversial anticancer drug laetrile.

Dr Robert Young, a clinical oncologist with the FDA, echoing concerns which have already been expressed and debated within the NCI, claims that such trials would be in violation of accepted ethical codes since no firm scientific evidence yet exists that the drug has any beneficial effects.

Both the FDA and the US medical establishment maintain stiff opposition to the use of the drug, which is derived from apricot kernels and is currently taken by thousands of cancer patients in the nation. The agency has issued notices warning that laetrile is "worthless" and that its cyanide content in particular is potentially dangerous.

However despite this uncompromising stand, FDA commissioner $\mathrm{Dr}$ Donald Kennedy, previously professor of human biology at Stanford University, has come under pressure from those who argue that although previous studies do not provide any conclusive evidence that laetrile has a beneficial effect, neither is there sufficient evidence to rule out such an effect.

The clinical trials have been proposed by the NCI following a retrospective study of laetrile patients which the institute, having frequently rejected the idea in the past, agreed to carry out last year.

Over 90 cases claiming evidence of a beneficial effect of laetrile treatment were submitted in response to a nationwide appeal, and a detailed study of 67 of these by a panel of oncologists revealed six patients who had received laetrile as their primary treatment, and were judged to have had a clinical response.

Announcing the results of the study last autumn, the NCI said that these would not normally be sufficient to suggest that a drug merit clinical tests over other candidate drugs. However it added that "because of widespread public use and interest in laetrile, the NCI will proceed with plans to evaluate the drug".

Subsequently the institute filed an "investigational new drug application" (IND) with the FDA in December. And although the agency has taken considerably longer than normal to approve the application-there have been detailed discussions with the NCI both about the protocol for the experiment, as well as on technical details about the quality, stability and purity of the substance to be testedthis is expected to be granted within a few weeks.

Dr Young's objection to granting approval is that "there is not adequate scientific data that would justify the

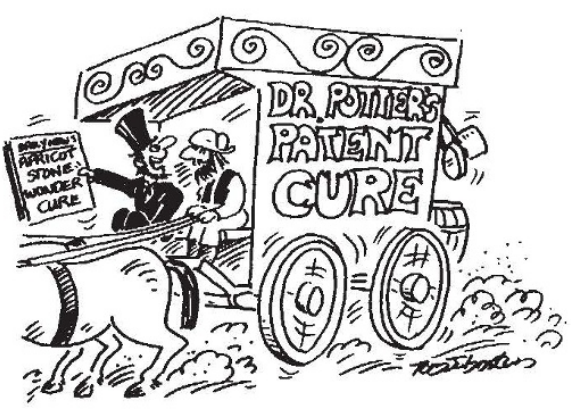

"To the nearest apricot farm!" test of the drug in human beings." In an interview with Nature last week he cited in particular the lack of evidence, accepted by the NCI, of the drug's efficacy in animal tests; and even the retrospective tests, he says, provides "no scientific data from which you can responsibly conclude that it was the taking of the drug that mitigated the disease".

In his petition, which Dr Young says reflects the feelings of a number of laboratory staff in the agency, he requests that laetrile should not be exempted from the provision of the Food and Drug Act, which require reports "adequate to justify the proposed clinical testing". And he criticises the agency for using a "sociopolitical argument", rather than a solid scientific case, to justify the trials.

If the FDA approves the cancer institute's IND, a six-month study will be carried out involving between 150 and 300 patients with different types of cancer; participation will be restricted to patients in whom all known therapies have been attempted.

Meanwhile the Supreme Court has agreed to rule on whether the FDA has the right to bar the use of laetrile as an anti-cancer drug, following the decision of a lower court that the need to show a drug is both "safe" and "effective" before being approved for sale or distribution does not apply to drugs used by terminally ill cancer patients.

In appealing the decision to the Supreme Court, the FDA has claimed that this ruling seriously limits its power to protect the public from unsafe and ineffective drugs, adding that it would be "virtually impossible to restrict the use of laetrile to the terminally ill".

David Dickson 